\title{
A bi-enzymatic cascade pathway towards FAHFAs
}

\author{
Yan Zhang, Bekir Engin Eser* and Zheng Guo*
}

\begin{abstract}
Recently discovered endogenous mammalian lipids fatty acid esters of hydroxy fatty acids (FAHFAs), proved to have antiinflammatory and anti-diabetic effects. Due to their extremely low abundancies in vivo, forging a feasible scenario for FAHFA synthesis is critical for their use in uncovering biological mechanism or clinical trials. Here, we showcase a fully enzymatic approach, a novel in vitro bi-enzymatic cascade system, enabling an effective conversion of nature-abundant fatty acid into FAHFAs. Two hydratases from $L$. acidophilus were used for converting unsaturated fatty acids to various stereospecific hydroxy fatty acids, followed by esterification with another fatty acid catalyzed by $C$. antarctica lipase A (CALA). Various FAHFAs were synthesized in a preparative scale using this bi-enzymatic approach in a one-pot two-step operation mode. In all, we demonstrated that hydratase-CALA system promises a sustainable solution to the synthesis of structure-diverse stereospecific FAHFAs.
\end{abstract}

\section{Introduction}

Diabetes mellitus is a metabolic disorder caused by insulin deficiency or insulin receptor resistance and characterized by high blood glucose levels. It was estimated that more than 400 million people are suffering from diabetes worldwide. ${ }^{[1]}$ Diabetes gives rise to several complications such as cardiovascular diseases, eye disease, renal and neurological problems, resulting in higher risk of morbidity and mortality. ${ }^{22]}$ Thus, diabetes has become a global disease with high economic burden on health systems. ${ }^{[3]}$ The traditional drugs used for diabetes treatment often have various side effects, like xerostomia or burning sensation in the mouth. ${ }^{[4]}$ Therefore, effective prevention and treatments using molecules of natural origin, with low production cost and minimal side effects, are desired. Recently, a new class of endogenous mammalian lipids i.e. fatty acid esters of hydroxy fatty acids (FAHFAs), discovered by Kahn and coworkers in 2014, have shown promising effect for potential treatment of diabetes and inflammatory diseases. ${ }^{[5]}$ Based on the structure of acyl chains and the ester bond position, FAHFAs are grouped in over 20 FAHFA families, which have been found in organisms ranging from plants to humans, especially in mammalian adipose tissue. ${ }^{\text {[5a }}$ 6] As shown in Figure 1, we illustrate the structures of several representative FAHFAs and FAHFA-containing triacylglycerols (FAHFA-TGs) that have been identified in mammalian tissues. Among them, palmitic acid esters of hydroxy stearic acids (PAHSAs) is one of the first reported and most abundant FAHFA family. To date, eight different regioisomers of PAHSAs (5-, 7-, 8-, 9-, 10-, 11-, 12-, and 13-) have been identified, potentially with significant variation in biological function and regulation. For instance, through oral administration to mice, 9-PAHSA has been demonstrated to display effective anti-diabetic effects via promoting insulin secretion and glucose transport, as well as prominent anti-inflammatory effects in dendritic cells. However, 5PAHSA is only correlative with insulin sensitivity, i.e. anti-diabetic effects. ${ }^{[5 a, 7]}$

[a] Y. Zhang, B. E. Eser, Z. Guo

Department of Biological and Chemical Engineering, Aarhus University Gustav Wieds Vej 10, 8000 Aarhus (Denmark)

E-mail: guo@bce.au.dk; bekireser@bce.au.dk

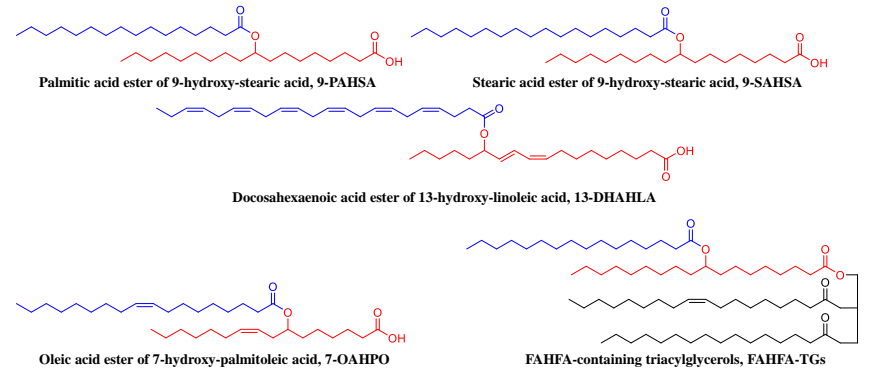

Figure 1. Structures of representative FAHFA families and lipid classes have been identified in mammalian cells and tissues. 9-PAHSA displays potent antidiabetic and anti-inflammatory. ${ }^{[5 a, 7]}$ Docosahexaenoic acid-derived FAHFAs (e.g. 13-DHAHLA) has also been shown to exert anti-inflammatory effects in both mice and humans. ${ }^{[6]]}$ FAHFA-TGs play key roles in regulation of inflammation and metabolic health. ${ }^{[20]}$

Due to the therapeutic potential toward diabetes and inflammation, the stereospecific and environmental friendly synthesis of FAHFAs has received substantial attention and remains of high interest (Scheme 1). However, studies on enzymes that synthesize FAHFAs in vivo are limited and the abundancies of FAHFAs in biological samples are extremely low and always naturally occurring as isomer mixtures; which make it highly challenging to enrich and isolate the FAHFA isomers from nature. ${ }^{[8]}$ In order to identify and characterize the biological properties of FAHFAs, several chemical synthesis strategies have been developed recently. The first synthetic case of FAHFAs was reported in 2014, where 9-PAHSA was produced starting from 1,9-nonanediol in eleven steps, however, the other analogs of 9PAHSA were not achieved with this strategy. ${ }^{[5 a]}$ In another method, several branched FAHFAs have been totally synthesized from terminal alkenes and alkynes in seven steps, including epoxide ring opening with acetylide carbanions mediated by boron trifluoride and hydrogenation of the alkyne function. ${ }^{[9]}$ Subsequently, several similar strategies using Grignard reagents have also been developed starting from non-racemic epichlorohydrin and monoprotected $\alpha, \omega$-diols to accomplish the introduction of the hydroxy group at different positions of the long chain, followed by esterification with another fatty acid molecule for enantioselective synthesis of FAHFAs. ${ }^{[10]}$

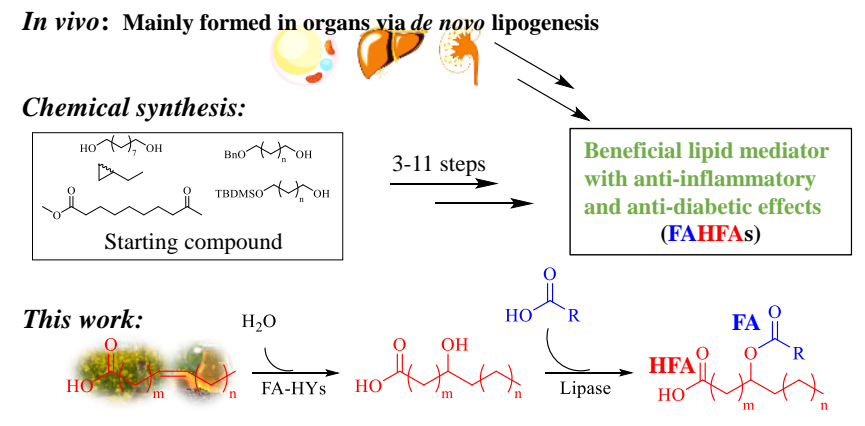

Scheme 1. Overview of the synthesis strategies for FAHFA preparation. In vivo: biosynthesis in de novo lipogenesis organs, like adipose tissue, liver and kidney; Chemical synthesis: starting from 1,9-nonanediol, S/R-(+)-epichlorohydrin, methyl 9-oxononanoate or monoprotected $\alpha, \omega$-diols; This work: bi-enzymatic cascade reaction by combination of hydratase and lipase for producing FAHFAs from renewable biomass. 
The key step of FAHFA synthesis is the introduction of the hydroxy group at different positions of the fatty acids (FAs) to produce hydroxy fatty acids (HFAs). Thus, the complexity of chemical synthetic strategies are caused by the challenge of hydroxylation, which involve harsh reaction conditions like high temperatures, hazardous organic solvents and elaborate group protecting steps. ${ }^{[11]}$ Many chemical methods have low selectivity and do not render the biologically active enantiomer. ${ }^{[10 a]}$ However, long-term biological studies as well as potential medical treatments and dietary supplements require sufficient supply of desired FAHFAs. In this respect, enzymatic methods have great potential for high-scale production of desired FAHFAs with excellent selectivity in a green manner. In contrast to chemical catalysts, Nature has developed its own chemical solutions to add hydroxyl group along carbon chain, which is an extensive list of enzymes, including lipoxygenases, cytochrome P450s and fatty acid hydratases. ${ }^{[12]}$ Among them, fatty acid hydratases (FAHs) are able to perform asymmetric synthesis of enantiomerically pure HFAs from abundant renewable unsaturated fatty acids. FAHs use water as a substrate and catalyze the hydration without the need for continuous supply of reducing cofactors (e.g. NAD $(P) H)$, which present an attractive green pathway for the production of HFAs. ${ }^{[13]}$ Although, until recently, low substrate promiscuity and limited regioselectivity of FAHs had been the main hurdle for their wider applicability, we demonstrated earlier that wild-type and rationally engineered variants of two FAHs from Lactobacillus acidophilus greatly expanded substrate scope and regioselectivity of fatty acid hydration leading to generation of various HFAs with different $-\mathrm{OH}$ positions (Table 1). ${ }^{[14]}$ Moreover, we have shown preparative scale enzymatic synthesis of a number of HFA products, with excellent regio- and stereoselectivity, using these wild-type and engineered FAHs (Table S1). Inspired by our diversiform FAH toolbox enabling the synthesis of various HFAs, we envisioned that we could use lipases in tandem with FAHs for the efficient synthesis of various FAHFAs, including a novel bienzymatic cascade pathway as shown in Scheme 1. Thus, on the basis of FAH driven conversion of FAs to HFAs, we executed the following work strategy: enabling the biotransformation of HFA to FAHFA, and then assembling the two conversion steps in tandem in one reaction system, affording a fully enzymatic synthesis of FAHFAs.

\section{Results and Discussion}

In a first round of experiments, we screened 21 commercially available lipases to explore their esterification activity toward palmitic acid (PA) and 12-hydroxystearic acid (12-HSA), selected as a model reaction for HFA to FAHFA conversion. Small-scale $(1 \mathrm{~mL})$ activity assays were performed at $60^{\circ} \mathrm{C}$ using toluene as solvent. To avoid the self-esterification of 12-HSA, the concentration of PA was excessive (2-fold) over 12-HSA. After 24 $\mathrm{h}$, the reactions were analyzed by GC-FID (see Supporting Information for method), and half of the tested lipases exhibited activity as shown in Table 2 (column 2). Among them, five candidates have shown high to excellent activities, with $>55 \%$ conversion. The active lipases can be categorized into two sources of strains: Candida antartica $A$ and Candida rugosa ( $C$. cylindracea is a former name of $C$. rugosa); even though they may be from different producers of different activities with/without genetic modification. However, their structures and substrate binding pockets are highly similar with tunnel-like binding sites. ${ }^{[15]}$ Considering the compatibility of $\mathrm{FAH}$ and a robust lipase, we decreased the screening reaction temperature to $30{ }^{\circ} \mathrm{C}$ in the second round of experiments. Interestingly, only CALA retained high conversion rate under lower temperature $\left(85.3 \%\right.$ at $30^{\circ} \mathrm{C}$ vs. $91.9 \%$ at $60^{\circ} \mathrm{C}$, Table 2), which indicated that CALA displays a
Table 1. Hydroxy fatty acids that can be synthesized from fatty acid precursors by two FAHs from $L$. acidophilus and their variants. ${ }^{[14]}$

\begin{tabular}{|c|c|c|}
\hline Enzyme & Fatty acid & Hydroxy fatty acid \\
\hline FA-HY2 & Palmitoleic acid $\left(16: 1^{\Delta 9}\right)$ & 10-Hydroxy-16:0 \\
\hline FA-HY2 & Oleic acid $\left(18: 1^{\Delta 9}\right)^{[a]}$ & 10-Hydroxy-18:0 \\
\hline FA-HY2 & Linoleic acid $\left(18: 2^{\Delta 9, \Delta 12}\right)^{[a]}$ & (S)-10-Hydroxy-cis-12-18:1 \\
\hline FA-HY2 & $\alpha$-Linolenic acid $\left(18^{3 \Delta 9, \Delta 12, \Delta 15}\right)^{[a]}$ & 10-Hydroxy-cis-12,cis-15-18:2 \\
\hline FA-HY2 & Arachidonic acid $\left(20: 4^{\Delta 5, \Delta 8, \Delta 11, \Delta 14}\right)$ & 12-Hydroxy-cis-5, cis-8, cis-14-20:3 \\
\hline FA-HY1 & cis-Vaccenic acid $\left(18: 1^{\Delta 11}\right)^{[\mathrm{a}]}$ & 12-Hydroxy-18:0 \\
\hline FA-HY1 & Linoleic acid $\left(18: 2^{\Delta 9, \Delta 12}\right)^{[a]}$ & $(R)-13-$ Hydroxy-cis-9-18:1 \\
\hline FA-HY1 & Pinolenic acid $\left(18: 3^{\Delta 5, \Delta 9, \Delta 12}\right)$ & 13-Hydroxy-cis-5,cis-9-18:2 \\
\hline FA-HY1 & $\mathrm{Y}$-Linolenic acid $\left(18: 3^{\Delta 6, \Delta 9, \Delta 12}\right)$ & 13-Hydroxy-cis-6, cis-9-18:2 \\
\hline FA-HY1 & $\alpha$-Linolenic acid $\left(18: 3^{\Delta 9, \Delta 12, \Delta 15}\right)^{[\mathrm{a}]}$ & (S)-13-Hydroxy-cis-9,cis-15-18:2 \\
\hline FA-HY1 & Stearidonic acid $\left(18: 4^{\Delta 6, \Delta 9, \Delta 12, \Delta 15}\right)$ & 13-Hydroxy-cis-6,cis-9, cis-15-18:3 \\
\hline FA-HY1 & Eicosadienoic acid $\left(20: 2^{\Delta 11, \Delta 14}\right)$ & 15-Hydroxy-cis-11-20:1 \\
\hline FA-HY1 & Mead acid $\left(20: 3^{\Delta 5, \Delta 8, \Delta 11}\right)$ & 12-Hydroxy-cis-5, cis-8-20:2 \\
\hline FA-HY1 & Sciadonic acid $\left(20: 3^{\Delta 5, \Delta 11, \Delta 14}\right)$ & 15-Hydroxy-cis-5, cis-11-20:2 \\
\hline FA-HY1 & $\begin{array}{l}\text { Dihomo-y-linolenic acid } \\
\left(20: 3^{\Delta 8, \Delta 11, \Delta 14}\right)\end{array}$ & 15-Hydroxy-cis-8,cis-11-20:2 $2^{[b]}$ \\
\hline FA-HY1 & Eicosatrienoic acid $\left(20: 3^{\Delta 11, \Delta 14, \Delta 17}\right)$ & $\begin{array}{l}\text { 12-Hydroxy-cis-14,cis-17-20:2 } \\
\text { 15-Hydroxy-cis-11,cis-17-20:2 }\end{array}$ \\
\hline FA-HY1 & Arachidonic acid $\left(20: 4^{\Delta 5, \Delta 8, \Delta 11, \Delta 14}\right)$ & 15-Hydroxy-cis-5,cis-8, cis-11-20:3 \\
\hline FA-HY1 & $\begin{array}{l}\text { Eicosapentaenoic acid } \\
\left(20: 5^{\Delta 5, \Delta 8, \Delta 11, \Delta 14, \Delta 17}\right)\end{array}$ & $\begin{array}{l}\text { 12-Hydroxy-cis-5, cis-8, cis- } 14, \text { cis- } \\
17-20: 4 \\
\text { 15-Hydroxy-cis-5, cis-8, cis- } 11, \text { cis- } \\
\text { 17-20:4 }\end{array}$ \\
\hline FA-HY1 & $\begin{array}{l}\text { Docosahexaenoic acid } \\
\left(22: 6^{\Delta 4, \Delta 7, \Delta 10, \Delta 13, \Delta 16, \Delta 19}\right)\end{array}$ & $\begin{array}{l}\text { 14-Hydroxy-cis-4,cis-7, cis- } 10, \text { cis- } \\
16, \text { cis-19-22:5 }\end{array}$ \\
\hline FA-HY2-T391S $S^{[c]}$ & $\mathrm{Y}$-Linolenic acid $\left(18: 3^{\Delta 6, \Delta 9, \Delta 12}\right)$ & 10-Hydroxy-cis-6,cis-12-18:2 \\
\hline FA-HY2-H393S & $\begin{array}{l}\text { Docosahexaenoic acid } \\
\left(22: 6^{\Delta 4, \Delta 7, \Delta 10, \Delta 13, \Delta 16, \Delta 19}\right)\end{array}$ & $\begin{array}{l}\text { 14-Hydroxy-cis-4,cis-7, cis-10, cis- } \\
\text { 16,cis-19-22:5 }\end{array}$ \\
\hline $\begin{array}{l}\text { FA-HY2- } \\
\text { T391S/H393S/1378 }\end{array}$ & $\begin{array}{l}\text { Dihomo-y-linolenic acid } \\
\left(20: 3^{\Delta 8, \Delta 11, \Delta 14}\right)\end{array}$ & (S)-12-Hydroxy-cis-8,cis-14-20:2 \\
\hline $\begin{array}{l}\text { FA-HY2- } \\
\text { T391S/H393S//378F }\end{array}$ & $\begin{array}{l}\text { Eicosapentaenoic acid } \\
\left(20: 5^{\Delta 5, \Delta 8, \Delta 11, \Delta 14, \Delta 17}\right)\end{array}$ & $\begin{array}{l}\text { (S)-12-Hydroxy-cis-5, cis-8, cis- } \\
14, \text { cis-17-20:4 }\end{array}$ \\
\hline
\end{tabular}

[a] Indicates the hydration of these substrates were used to verify the cascade reaction in a preparative scale in this study. ${ }^{\text {[b] }}$ Trace amount of 12-hydroxy-cis8,cis-14-20:2 product has also been detected. ${ }^{[c]}$ Only the variants that exhibited the highest conversion were displayed.

prominent activity and a broad temperature range for synthesis of FAHFAs. Actually, the substrate specificity of CALA had been explored in many studies, which demonstrated that CALA exhibited a relative high activity towards straight-chained primary alcohols and carboxylic acids, as well as sterically hindered secondary and tertiary alcohols. However, low or no activity was observed towards very short-chain acids. ${ }^{[16]}$ In addition, CALA was also used for enzymatic synthesis of fatty acid polyesters (estolide) from 12-hydroxy-9-cis-octadecenoic acid (ricinoleic acid). ${ }^{[17]}$ These results indicate that CALA has a unique 
applicability for the esterification of secondary alcohols (like HFAs) and long-chain FAs, which is an excellent candidate for production of FAHFAs. Thus, CALA was chosen for further investigation in our case.

Table 2. Lipase screening for fatty acid and hydroxy fatty acid esterification ${ }^{[a]}$.

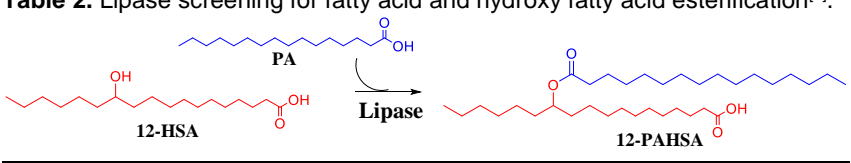

\begin{tabular}{|c|c|c|}
\hline Commercial lipase & $\begin{array}{l}\text { Conv. } \% \\
\left(60^{\circ} \mathrm{C}\right)\end{array}$ & $\begin{array}{l}\text { Conv. } \\
\left(30^{\circ} \mathrm{C}\right)\end{array}$ \\
\hline CALA (Immobilized Candida antartica lipase A from Codexis) & 91.9 & 85.3 \\
\hline CALB (Liquid/Unimmobilized Candida antartica lipase B) & 4.0 & $N D^{[b]}$ \\
\hline $\begin{array}{l}\text { Novozyme } 435 \text { FG (Candida antartica lipase B immobilized on a } \\
\text { macroporous acrylic resin) }\end{array}$ & 6.6 & ND \\
\hline Lipozyme 435 (Candida antartica lipase B immobilized on silica) & 27.5 & ND \\
\hline $\begin{array}{l}\text { Lipozyme TL IM (Lipase from Thermomyces lanuginosus } \\
\text { immobilized on silica) }\end{array}$ & 1.7 & ND \\
\hline $\begin{array}{l}\text { Lipozyme RM IM (Lipase from Rhezomucor miehei immobilized on } \\
\text { a macroporous ion-exchange resin) }\end{array}$ & ND & ND \\
\hline $\begin{array}{l}\text { NS-40042 (Genetically modified lipase from Thermomyces } \\
\text { lanuginosus) }\end{array}$ & 4.1 & ND \\
\hline $\begin{array}{l}\text { NS-40079 (Genetically modified lipase from Thermomyces } \\
\text { lanuginosus) }\end{array}$ & 10.2 & ND \\
\hline Lipase A "Amano" 12 (From Aspergillus niger) & ND & ND \\
\hline Lipase D “Amano” 350 (From Rhizopus delemar) & ND & ND \\
\hline Lipase G "Amano" 50 (From Penicillium camemberti) & ND & ND \\
\hline Lipase M “Amano" 10 (From Mucor javanicus) & ND & ND \\
\hline Lipase OF (From Candida cylindracea (C.rugosa)) & 56.5 & 5.1 \\
\hline Lipase MY (From Candida cylindracea (C.rugosa)) & 81.5 & 19.5 \\
\hline Lipase F-AP15 (From Rhizopus oryzae) & ND & ND \\
\hline Lipase PS-D “Amano" I (From Burkholderia cepacia) & ND & ND \\
\hline Lipase from Candida rugosa (Sigma, powder) & 63.4 & 21.1 \\
\hline Lipase from Candida cylindracea (Sigma, powder) & 69.7 & 9.5 \\
\hline Lipase from Porcine pancreas (Sigma, powder) & 1.2 & ND \\
\hline $\begin{array}{l}\text { Lipase from Candida rugosa immobilized on Immobead } 150 \text { (Sigma, } \\
\text { powder) }\end{array}$ & 3.6 & ND \\
\hline $\begin{array}{l}\text { Lipase AK from Pseudomonas fluorescens immobilized on } \\
\text { Immobead } 150 \text { (Sigma, powder) }\end{array}$ & ND & ND \\
\hline
\end{tabular}

[a] Reaction system: Lipase- $10 \mathrm{mg}, 10 \mathrm{mg} / \mathrm{ml} \mathrm{PA}, 5 \mathrm{mg} / \mathrm{ml} 12-\mathrm{HSA}$, Toluene, 30 or $60{ }^{\circ} \mathrm{C}, 250 \mathrm{rpm}, 24$ h. ${ }^{[b]} \mathrm{ND}$ : not detected.

Subsequently, the reaction was scaled up to $20 \mathrm{~mL}$ for product preparation and identification (palmitic acid esters of 12hydroxystearic acids, 12-PAHSA) under the same conditions. From time-course analysis (Figure S6), it was obvious that there was no significant difference when reactions were performed at $30{ }^{\circ} \mathrm{C}$ or $60^{\circ} \mathrm{C}$ (final conversion was slightly higher at $60^{\circ} \mathrm{C}$ ), which was consistent with the small scale screening result. The reaction rate started decreasing after 1.5-2.0 $\mathrm{h}$, and reached
$86.8 \%$ or $90.5 \%$ conversion levels at $8 \mathrm{~h}$ for $30{ }^{\circ} \mathrm{C}$ or $60{ }^{\circ} \mathrm{C}$ respectively. Then, purification of the product was carried out on preparative TLC plate, giving $78.1 \%$ isolated molar yield and $90.1 \%$ purity. The structure of isolated product was confirmed by ${ }^{1} \mathrm{H}$ and ${ }^{13} \mathrm{C}$ NMR (Figure S18-19).

We also simply compared the catalytic capacity of CALA under different conditions, in terms of reaction solvents and the ratio of PA/12-HSA (Table S2). As anticipated, the esterification activity of CALA was completely lost in aqueous phase. The conversion rate improved along with the increasing organic solvent ratio (Table S2, entry 1-3), and achieved the yield of $43.3 \%$ and $69.9 \%$ in $\mathrm{Kpi} /$ Toluene $(1: 1 \mathrm{v} / \mathrm{v})$ and pure toluene, respectively. We next investigated the effect of PA/12-HSA ratio on the production of 12-PAHSA. The yield of 12-PAHSA improved when higher PA/12HSA ratio was reached. By increasing the PA concentration to 10 $\mathrm{mg} / \mathrm{mL}$ and lowering the $12-\mathrm{HSA}$ concentration to $1 \mathrm{mg} / \mathrm{mL}$, we were able to achieve the highest conversion at $95.1 \%$ (Table S2, entry 3-5). Moreover, we performed a control reaction without PA substrate (only involved 12-HSA). As expected there was no peak observed for 12-PAHSA, however, a new peak (Figure S10) was observed with less than $10 \%$ conversion which might be caused by the self-esterification of 12-HSA. Interestingly, this product was not observed when PA was present in the reaction system, indicating lower reactivity of HSA as an acyl donor.

After demonstrating efficient enzymatic conversion of a HFA to FAHFA, we next explored a bi-enzymatic cascade reaction where $\mathrm{FAH}$ and CALA are combined for direct conversion of renewable FAs into FAHFAs. As described in the literature, one of the hurdles in the biotransformation of plant oils is the low fatty acid transport rate across the membrane of the cells from or into the media. ${ }^{[18]}$ Since we initially aimed using whole cells expressing hydratase as the biocatalyst in the first step of our cascade, we firstly investigated FA and HFA transport through the membrane of $E$. coli cells. After performing the hydration of linoleic acid (LA) using the E. coli whole-cells (containing FA-HY1) as catalyst, both LA and 13-hydroxy-cis-octadec-9-enoic acid (13HODA) were observed in higher concentration in the cells (over 4-fold than the supernatant, Figure S7), which indicated that the HFA product was trapped in majority inside the cells. To ensure a sufficient HFA interaction with the second enzyme CALA, we chose to use cell lysates of $E$. coli expressing $F A H s$ in the cascade reaction, facilitating FAHFAs preparation.

As described above, no esterification reaction takes place between PA and 12-HSA when CALA was subjected to singlephase aqueous buffer. Thus, in order to identify the optimal solvent system for the cascade, we evaluated the conversion rate of FA-HY1 and CALA in different biphasic systems (Figure 2A). Several organic solvents with the $\log \mathrm{P}$ value varying from 2.5 to 5.8 were selected, as well as three versatile eco-friendly solvents (2-MeTHF, CPME and GVL), which have been shown as promising bio-solvents in lipase-catalyzed reactions. ${ }^{[19]}$ Obviously, due to the poor organic solvent tolerance and low stability, the conversion rate of LA by FA-HY1 in nine of the biphasic systems were lower than $10 \%$ compared with $74.5 \%$ in single Kpi buffer. CALA displayed similar performance, with less than $30 \%$ esterification in most of the biphasic systems. However, 90.4\% conversion was observed in Kpi/Toluene system, which seems to be optimum for the bi-enzymatic cascade. Three green solvents are not suitable for either hydratase or CALA in our case. 

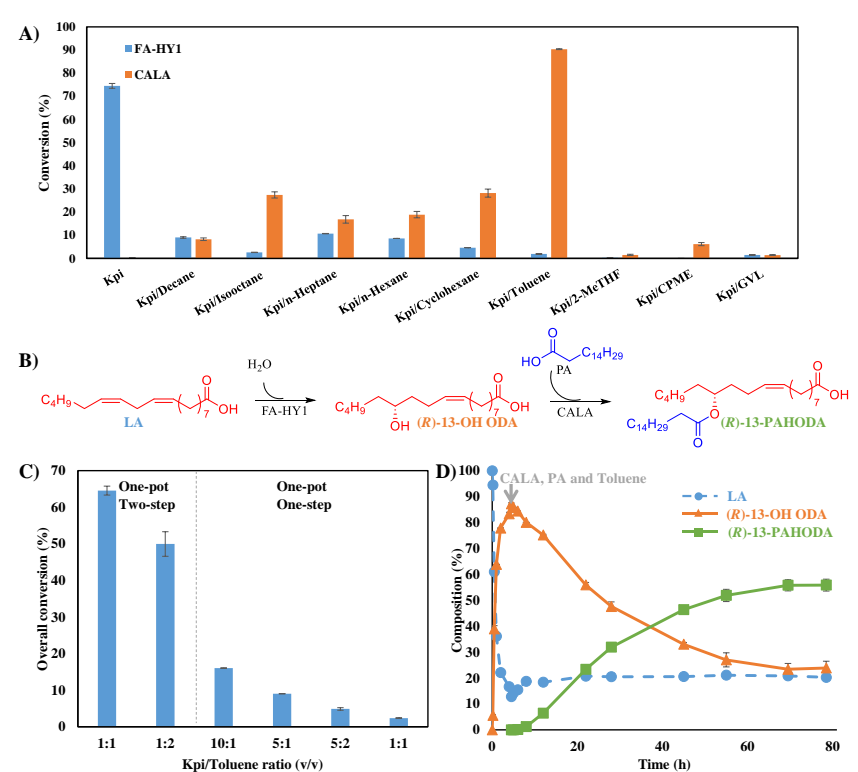

Figure 2. Cascades for the transformation of LA into 13-PAHODA. A) Organic solvent tolerance of FA-HY1 and CALA. Kpi: $100 \mathrm{mM}$ potassium phosphate buffer at $\mathrm{pH}$ 6.0; 2-MeTHF: 2-methyltetrahydrofuran; CPME: cyclopentyl methy ether; GVL: $\gamma$-valerolactone. The volume ratio of Kpi/organic solvent is 1:1. B) Reaction scheme for the cascade. C) The influence of reaction mode and solvent ratio to the cascade reaction. D) Time dependent one-pot two-step bienzymatic cascade for biotransformation of LA and PA into 13-PAHODA. The first hydration of LA step was performed in single aqueous condition, including $50 \mathrm{~mL}$ supernatant of cell lysate (ultrasonication of $50 \mathrm{mg} / \mathrm{mL}$ cells in Kpi buffer) and $100 \mathrm{mg} \mathrm{LA}$; the second step was started by the addition of $500 \mathrm{mg}$ CALA, $200 \mathrm{mg} \mathrm{PA}$ and $50 \mathrm{~mL}$ toluene.

We further investigated the operation mode in $\mathrm{Kpi} /$ Toluene biphasic system by comparing the overall conversions in one-pot one-step (all of the starting materials and enzymes were added at the beginning) or one-pot two-step approach (the hydration reaction of one unsaturated fatty acid was first performed in single Kpi buffer, followed by the addition of CALA, toluene and another fatty acid). As shown in Figure $\mathbf{2 C}$, different Kpi/Toluene ratios were evaluated for both reaction modes. The highest overall conversion was achieved at $65 \%$ with one-pot two-step mode using 1:1 Kpi/Toluene ratio. With one-pot one-step mode, all of the tested solvent ratios resulted in less than $20 \%$ overall conversion, which can be attributed to the instability of FAHs in the presence of organic solvent. Therefore, for all further experiments, a one-pot two-step operation was followed. Under the optimized one-pot two-step conditions, the enzymatic synthesis of palmitic acid ester of 13-hydroxy-cis-octadec-9-enoic acid (13-PAHODA) from LA and PA was scaled up to $100 \mathrm{~mL}$ in a preparative scale. FA-HY1 almost completely converted LA into its $13-\mathrm{OH}$ product (13-HODA) in $8 \mathrm{~h}$ (Figure 2D). The second esterification step took significantly longer after adding CALA, PA and toluene to the sample pot. The final composition of 13PAHODA amounted up to $56 \%$ at plateau stage. In other words, the cascade reaction reaches an equilibrium, which might be caused by a reversible balance between hydrolysis and esterification.

Considering differential regulation and biological activity of FAHFA regioisomers and encouraged by the broad substrate promiscuity of our FAHs library, the substrate scope of this proofof-concept bi-enzymatic cascade was further expanded by employing the above one-pot two-step approach for production of different FAHFAs (Figure 3). The typical hydratase, FA-HY2, can only add water on $\Delta 9$ double bonds to produce $10-\mathrm{OH}$ products, whereas the unique FA-HY1 preferably hydrates double bonds other than $\Delta 9$ to generate $12-\mathrm{OH}, 13-\mathrm{OH}, 14-\mathrm{OH}$ and $15-\mathrm{OH}$ products. ${ }^{[14]}$ Therefore, several pairs of $\mathrm{FAH}$-substrate, that exhibited high conversion rate in our previous study ${ }^{[14 a]}$, were chosen for FAHFA preparation. By using either FA-HY1 or FAHY2, oleic acid (OA), LA, cis-vaccenic acid (CVA) and $\alpha$-linolenic acid (ALA) were converted to corresponding HFAs with different -OH position, followed by the esterification with PA catalyzed by CALA. From the preparative reactions in $100 \mathrm{~mL}$ media, several branched FAHFA products were synthesized, and the overall conversion of FAHFA products can be achieved at $28-67 \%$. Since the polarity of the remaining excess fatty acid substrates and FAHFA products are quite similar, trailing phenomena of these compounds on silica gel rendered the separation of fatty acids and FAHFAs very difficult. To eliminate the trailing phenomena caused by the strong interaction between the carboxyl groups of FAHFA and silica gel for a better FAHFA isolation, methylation of reaction mixture before purification was performed to convert the carboxyl groups to corresponding methyl esters. On the other hand, methyl esters (or other esters) of FAHFAs can afford similar reactivity as free FAHFAs as acyl donors for interesterification or biological incorporation into triglycerides, which are the major form of FAHFAs in the tissues. ${ }^{[20]}$ As shown in Figure S8, a better resolution of fatty acids and FAHFA products was observed on TLC plate after methylation. Then, the methylated FAHFA products were purified by preparative TLC plate. Among them, palmitic acid ester of 12-hydroxy steric acid (12-PAHSA), by converting CVA to 12-HSA (catalyzed by FA-HY1) and followed by esterification with PA (catalyzed by CALA), was isolated in a highest molar yield of $42 \%$. The majority of the purified FAHFA products had a purity of $>90 \%$, as determined by GC-FID analysis. The structures of isolated products were confirmed by ${ }^{1} \mathrm{H}$ and ${ }^{13} \mathrm{C}$ NMR (Figure S20-31). The absolute configurations of three products i.e. palmitic acid ester of 10-hydroxy-cis-octadec-12enoic acid (10-PAHODA), palmitic acid ester of 13-hydroxy-cisoctadec-9-enoic acid (13-PAHODA) and palmitic acid ester of 13 hydroxy-cis-9,cis-15-octadecadienoic acid (13-PAHODDA) can be given as $(R),(S)$ and $(R)$, respectively, based on our previous analysis of the corresponding chiral HFAs. ${ }^{[14]}$

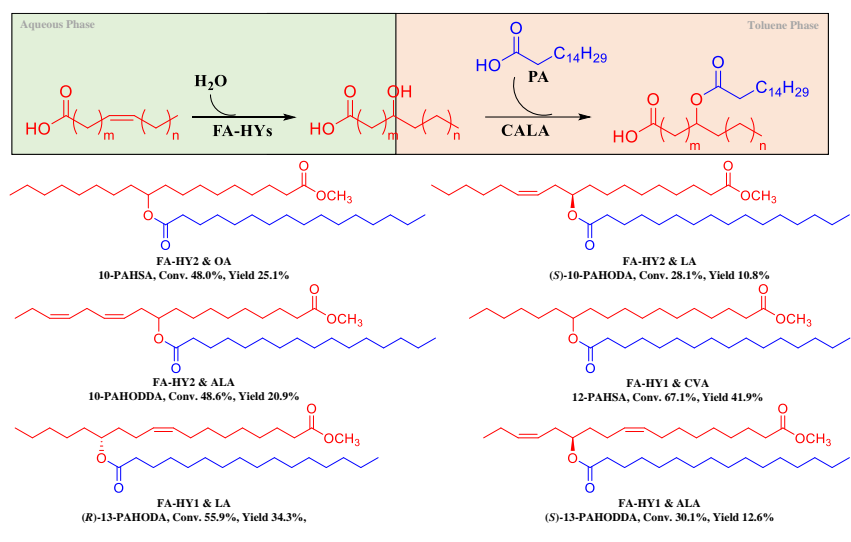

Figure 3. Substrate scope of hydratase-lipase cascade reaction. The reactions were performed in a one-pot two-step procedure as described above. Conversion $=[F A H F A]_{\text {final }} /[\text { Unsaturated fatty acid }]_{\text {initial }} \times 100 \%$; determined via GC-FID as described in the Supporting Information. Yield: isolated molar yield of methylated FAHFA products.

\section{Conclusion}

In summary, we have successfully demonstrated that the medically important endogenous lipids of FAHFAs can be synthesized enzymatically from renewable fatty acids using FAHs-CALA catalytic system, either by a two-step synthesis or by a bi-enzymatic cascade of one-pot two-step process. To our 
knowledge, the only other study that reported synthesis of fatty acid estolides (including FAHFAs) by enzymatic cascade approach utilizing hydratase and lipase is a patent, ${ }^{[21]}$ where oleate hydratase (OhyA) was used for hydration of unsaturated FAs at $\Delta 9$ position to produce only $10-\mathrm{OH}$ products. By utilizing two different FAHs from $L$. acidophilus and various fatty acids, the product profile of our system was greatly expanded to prepare various stereospecific isomers of FAHFAs corresponding to possibly differential regulation and biological functions. Our results suggested two types of lipases from $C$. antartica $A$ and $C$. Rugosa are highly selective and active catalyst for esterification between FAs and HFAs. Lipases from both strains exhibit similar tunnel-like binding sites with ample space, which is capable to accept bulky secondary alcohol donor; thus allowing effective interaction of two reactants with large steric hindrance. ${ }^{[15,22]}$ Our approach paves the way for enzymatic synthesis of a variety of FAHFAs from sustainable fatty acids in a large scale, enabling their production for use in pre-clinical and clinical studies as well as for applications in medications and as dietary supplements. We honestly admit this approach is still in the conceptual stage due to the low substrate loading and incomplete transformation. Protein engineering to further increase the activity and to expand the substrate diversity of $\mathrm{FAHs}$, as well as reaction optimization studies are ongoing in our lab to improve the product yield and broaden product spectra. Moreover, lipoxygenases and cytochrome P450s, which also add $-\mathrm{OH}$ groups on FAs with complementary selectivity and substrate scope to FAHs, can further diversify the product spectra of enzymatically synthesized FAHFAs.

\section{Acknowledgements}

This work was supported by Novo Nordisk Foundation (grant NNF16OC0021740) and by AUFF-NOVA from Aarhus Universitets Forskningsfond (AUFF-E-2015-FLS-9-12). We thank Prof. Jun Ogawa from Kyoto University for providing the plasmids of $\mathrm{FA}-\mathrm{HY} 1$ and $\mathrm{FA}-\mathrm{HY} 2$.

\section{Conflict of interest}

The authors declare no conflicts of interest.

Keywords: bioactive FAHFAs • enzymatic synthesis • fatty acid hydratase $\cdot$ lipase $\cdot$ renewable biomass

[1] K. Ogurtsova, U. Linnenkamp, R. F. J. D. da, Y. Huang, L. Guariguata, D. Cavan, N. H. Cho, J. E. Shaw, L. E. Makaroff, Diabetes Res Clin Pract 2017, 128, 40-50.

[2] a) O. Pinhas-Hamiel, P. Zeitler, Lancet 2007, 369, 1823-1831; b) Diabetes Care 2013, 36, S67-S74; c) M. Stolar, Am. J. Med. 2010, 123 S3-S11.

[3] Y. Huang, S. Karuranga, B. Malanda, D. R. R. Williams, Diabetes Res Clin Pract 2018, 140, 351-352.

[4] I. D. Federation, International Diabetes Federation 2017, Brussels, Belgium.

[5] a) Mark M. Yore, I. Syed, Pedro M. Moraes-Vieira, T. Zhang, Mark A Herman, Edwin A. Homan, Rajesh T. Patel, J. Lee, S. Chen, Odile D. Peroni, Abha S. Dhaneshwar, A. Hammarstedt, U. Smith, Timothy E. McGraw, A. Saghatelian, Barbara B. Kahn, Cell 2014, 159, 318-332; b) J. Lee, P. M. Moraes-Vieira, A. Castoldi, P. Aryal, E. U. Yee, C. Vickers, O. Parnas, C. J. Donaldson, A. Saghatelian, B. B. Kahn, J. Biol. Chem. 2016, 291, 22207-22217; c) L. Balas, C. Feillet-Coudray, T. Durand, Chem. - Eur. J. 2018, 24, 9463-9476.
[6] a) M. Brezinova, O. Kuda, J. Hansikova, M. Rombaldova, L. Balas, K Bardova, T. Durand, M. Rossmeisl, M. Cerna, Z. Stranak, J. Kopecky, Biochim. Biophys. Acta, Mol. Cell Biol. Lipids 2018, 1863, 126-131; b) T. Hu, M. Lin, D. Zhang, M. Li, J. Zhang, Anal. Bioanal. Chem. 2018, 410 7415-7428; c) O. Kuda, M. Brezinova, M. Rombaldova, B. Slavikova, M. Posta, P. Beier, P. Janovska, J. Veleba, J. Kopecky, E. Kudova, T Pelikanova, Diabetes 2016, 65, 2580-2590; d) O. Kuda, M. Brezinova, J. Silhavy, V. Landa, V. Zidek, C. Dodia, F. Kreuchwig, M. Vrbacky, L. Balas, T. Durand, N. Hubner, A. B. Fisher, J. Kopecky, M. Pravenec, Diabetes 2018, 67, 1190-1199; e) Q.-F. Zhu, J.-W. Yan, T.-Y. Zhang, H.-M. Xiao, Y.-Q. Feng, Anal Chem 2018, 90, 10056-10063; f) Y. Ma, T. Kind, A. Vaniya, I. Gennity, J. F. Fahrmann, O. Fiehn, J. Cheminf. 2015, 7, 53/51 $53 / 55$

[7] a) P. M. Moraes-Vieira, A. Saghatelian, B. B. Kahn, Diabetes 2016, 65, 1808-1815; b) E. Pflimlin, M. Bielohuby, M. Korn, K. Breitschopf, M. Loehn, P. Wohlfart, A. Konkar, M. Podeschwa, F. Baerenz, A. Pfenninger, U. Schwahn, T. Opatz, M. Reimann, S. Petry, N. Tennagels, Cell Metab. 2018, 28, 217-227.e213.

[8] a) M. E. Ertunc, B. P. Kok, W. H. Parsons, J. G. Wang, D. Tan, C. J. Donaldson, A. F. M. Pinto, J. M. Vaughan, N. Ngo, K. M. Lum, C. L. Henry, A. R. Coppola, M. J. Niphakis, B. F. Cravatt, E. Saez, A. Saghatelian, J. Biol. Chem. 2020, 295, 5891-5905; b) M. G. Kokotou, Biomolecules 2020 , 10, 1092.

[9] L. Balas, J. Bertrand-Michel, F. Viars, J. Faugere, C. Lefort, S. CasparBauguil, D. Langin, T. Durand, Org. Biomol. Chem. 2016, 14, 9012-9020.

[10] a) A. T. Nelson, M. J. Kolar, Q. Chu, I. Syed, B. B. Kahn, A. Saghatelian D. Siegel, J. Am. Chem. Soc. 2017, 139, 4943-4947; b) H. Wang, T. Chang, S. Konduri, J. Huang, A. Saghatelian, D. Siegel, J. Antibiot. 2019, 72, 498-506; c) O. G. Mountanea, D. Limnios, M. G. Kokotou, A. Bourboula, G. Kokotos, Eur. J. Org. Chem. 2019, 2019, 2010-2019.

[11] a) J. Jin, U. Hanefeld, Chem. Commun. (Camb.) 2011, 47, 2502-2510; b) V. Resch, U. Hanefeld, Catalysis Science \& Technology 2015, 5, 1385-1399.

[12] a) J. C. Lewis, P. S. Coelho, F. H. Arnold, Chemical Society Reviews 2011, 40, 2003-2021; b) F. Feyza Ozgen, M. E. Runda, B. O. Burek, P. Wied, J. Z. Bloh, R. Kourist, S. Schmidt, Angew Chem Int Ed Engl 2019; c) K. Zorn, I. Oroz-Guinea, H. Brundiek, U. T. Bornscheuer, Prog. Lipid Res. 2016, 63, 153-164

[13] a) H. Groeger, Angew. Chem., Int. Ed. 2014, 53, 3067-3069; b) Y. Zhang, B. E. Eser, P. Kristensen, Z. Guo, Chinese Journal of Chemical Engineering 2020, 28, 2051-2063.

[14] a) B. E. Eser, M. Poborsky, R. Dai, S. Kishino, A. Ljubic, M. Takeuchi, C Jacobsen, J. Ogawa, P. Kristensen, Z. Guo, ChemBioChem 2020, 21, 550-563; b) A. Hirata, S. Kishino, M. Takeuchi, N. Kitamura, J. Ogawa, S.-B. Park, J Lipid Res 2015, 56, 1340-1350.

[15] a) M. Widmann, P. B. Juhl, J. Pleiss, BMC Genomics 2010, 11, 123; b) S. H. Albayati, M. Masomian, S. N. H. Ishak, M. S. B. M. Ali, A. L. Thean, F. B. M. Shariff, N. D. B. M. Noor, R. N. Z. R. A. Rahman, Catalysts 2020 10,747

[16] O. Kirk, M. W. Christensen, Org. Process Res. Dev. 2002, 6, 446-451.

[17] a) A. Arslan, A. Rancke-Madsen, J. Brask, Catalysts 2020, 10, 835; b) A Bodalo-Santoyo, J. Bastida-Rodriguez, M. F. Maximo-Martin, M. C Montiel-Morte, M. D. Murcia-Almagro, Biochem. Eng. J. 2005, 26, 155158.

[18] a) E.-Y. Jeon, J.-H. Seo, W.-R. Kang, M.-J. Kim, J.-H. Lee, D.-K. Oh, J.B. Park, ACS Catal. 2016, 6, 7547-7553; b) E.-Y. Jeon, J.-W. Song, H. J. Cha, S.-M. Lee, J. Lee, J.-B. Park, J. Biotechnol. 2018, 281, 161-167.

[19] a) G. de Gonzalo, A. R. Alcántara, P. Domínguez de María ChemSusChem 2019, 12, 2083-2097; b) K. Watanabe, N. Yamagiwa, Y. Torisawa, Org. Process Res. Dev. 2007, 11, 251-258; c) C. Aranda, G. de Gonzalo, Molecules 2020, 25, 3016; d) F. G. Calvo-Flores, M. J. Monteagudo-Arrebola, J. A. Dobado, J. Isac-Garcia, Top. Curr. Chem. 2018, 376, 1-40.

[20] D. Tan, M. E. Ertunc, S. Konduri, J. Zhang, A. M. Pinto, Q. Chu, B. B. Kahn, D. Siegel, A. Saghatelian, J. Am. Chem. Soc. 2019, 141, 87988806.

[21] C. G. Boeriu, A. Todea, I. W. C. E. Arends, L. G. Otten, US20180073046 2018. 
[22] a) D. J. Ericsson, A. Kasrayan, P. Johansson, T. Bergfors, A. G. Sandstroem, J.-E. Baeckvall, S. L. Mowbray, J. Mol. Biol. 2008, 376, 109119; b) P. Grochulski, Y. Li, J. D. Schrag, F. Bouthillier, P. Smith, D. Harrison, B. Rubin, M. Cygler, Journal of Biological Chemistry 1993, 268, 12843-12847. 


\section{Entry for the Table of Contents}

Fully enzymatic synthesis of FAHFAs: Various hydroxy fatty acids with different $-\mathrm{OH}$ positions can be synthesized from renewable fatty acids by wild-type and engineered fatty acid hydratases, which can be cascaded with lipase to prepare value-added FAHFAs with potential medical values.

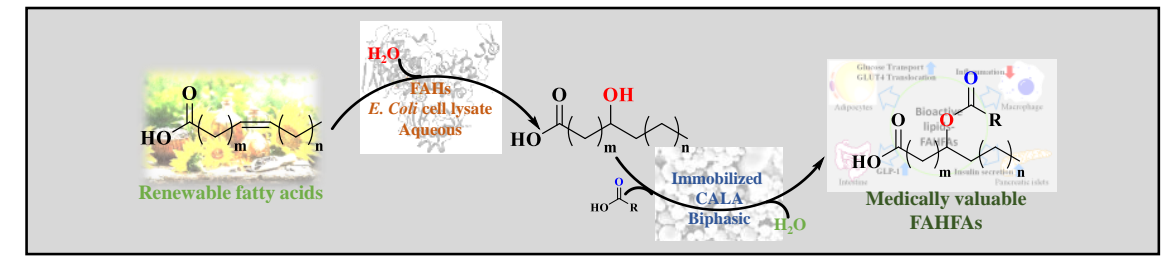

